\title{
Video Article \\ Determination of Inorganic Arsenic in a Wide Range of Food Matrices using Hydride Generation - Atomic Absorption Spectrometry.
}

\author{
Maria B. de la Calle ${ }^{1}$, Vicenta Devesa ${ }^{2}$, Yiannis Fiamegos ${ }^{1}$, Dinoraz Vélez ${ }^{2}$ \\ ${ }^{1}$ European Commission, Joint Research Centre \\ ${ }^{2}$ Metal Trace Element Laboratory, IATA-CSIC
}

Correspondence to: Maria B. de la Calle at Maria.DE-LA-CALLE@ec.europa.eu

URL: https://www.jove.com/video/55953

DOI: doi:10.3791/55953

Keywords: Environmental Sciences, Issue 127, Inorganic arsenic, rice, grain, vegetables, mushrooms, algae, fish, hydride generation.

Date Published: 9/1/2017

Citation: de la Calle, M.B., Devesa, V., Fiamegos, Y., Vélez, D. Determination of Inorganic Arsenic in a Wide Range of Food Matrices using Hydride Generation - Atomic Absorption Spectrometry.. J. Vis. Exp. (127), e55953, doi:10.3791/55953 (2017).

\section{Abstract}

The European Food Safety Authority (EFSA) underlined in its Scientific Opinion on Arsenic in Food that in order to support a sound exposure assessment to inorganic arsenic through diet, information about distribution of arsenic species in various food types must be generated. A method, previously validated in a collaborative trial, has been applied to determine inorganic arsenic in a wide variety of food matrices, covering grains, mushrooms and food of marine origin (31 samples in total). The method is based on detection by flow injection-hydride generationatomic absorption spectrometry of the iAs selectively extracted into chloroform after digestion of the proteins with concentrated $\mathrm{HCl}$. The method is characterized by a limit of quantification of $10 \mu \mathrm{g} / \mathrm{kg}$ dry weight, which allowed quantification of inorganic arsenic in a large amount of food matrices. Information is provided about performance scores given to results obtained with this method and which were reported by different laboratories in several proficiency tests. The percentage of satisfactory results obtained with the discussed method is higher than that of the results obtained with other analytical approaches.

\section{Video Link}

The video component of this article can be found at https://www.jove.com/video/55953/

\section{Introduction}

Since January 2016 maximum levels for inorganic arsenic (iAs) in several rice commodities have been included in Commission Regulation (EC) $1881 / 2006$ setting maximum levels for certain contaminants in foodstuffs ${ }^{1}$ with $0.10 \mu \mathrm{g} / \mathrm{L}$ for rice destined for the production of food for infants and young children, $0.20 \mu \mathrm{g} / \mathrm{L}$ for non-parboiled milled rice (polished or white rice), $0.25 \mu \mathrm{g} / \mathrm{L}$ for parboiled rice and husked rice and $0.30 \mu \mathrm{g} / \mathrm{L}$ for rice waffles, rice wafers, rice crackers and rice cakes. This update of the European legislation for contaminants in food followed the Scientific Opinion on Arsenic in Food of the European Food Safety Authority (EFSA) ${ }^{2}$ in which it is estimated that the exposure through diet to iAs for average and high consumers in Europe is such that can pose a risk to some consumers, keeping in mind that chronic exposure to iAs causes cancer of the lung, skin and bladder, and skin lesions. In the scientific report of EFSA on Dietary exposure to inorganic arsenic in the European population $^{3}$, published in 2014 , it is concluded that the main contributors to iAs in the diet for consumers of all ages are processed products made of cereals other than rice and that also rice, milk, dairy products and drinking water contribute significantly to iAs intake, with milk and dairy products being the main contributors for toddlers and infants.

In 2010 the European Union Reference Laboratory for Heavy Metals in Feed and food, EURL-HM, ran a proficiency test, IMEP-107, for the determination of iAs in rice, demonstrating that it was possible to determine iAs in rice with sufficient accuracy, regardless of the analytical method used ${ }^{4}$.

Several analytical methods have been validated for the determination of iAs in foodstuffs. China was the first country to introduce in its legislation a maximum level for iAs in rice. To make the implementation of legislation possible, a standard method was published in 2003 for the determination of what in the standard is called "abio-arsenic"5. The European Committee for Standardisation (CEN), published in 2008 a standardized method, EN 15517:2008, for the determination of iAs in seaweed ${ }^{6}$. The two methods are based on the use of optimized conditions to generate arsine only from iAs. In that way separation of iAs from other arsenic species that can also generate arsenic hydride is not needed. The final determination is done by atomic fluorescence ${ }^{5}$ or by hydride generation atomic absorption spectrometry, HG-AAS ${ }^{6}$. However, it is difficult to set the exact conditions to generate arsenic hydride without suffering from interference of other arsenic compounds and all the iAs mass fractions in algae reported in IMEP-112 (PT organized by the EURL-HM) obtained with those two methods, were scored as unsatisfactory ${ }^{7}$ Organoarsenic species, such as monomethylarsonic acid (MMA), dimethylarsinic acid (DMA), and arsenosugars present in algae samples, can generate volatile hydrides too and could interfere in the determination of iAs leading to a positive bias in the results ${ }^{8}$. 
Recently, CEN published a new standard method, EN 16802:2016, for the determination of iAs in foodstuffs of marine and plant origin using HPLC-ICP-MS ${ }^{9}$. Not all laboratories are equipped with that type of instrumentation and non-expensive, straight-forward methods are needed, in particular in countries with less developed laboratory infrastructures.

In 2012 CEN standardized a method for the determination of iAs in animal feeding stuffs by HG-AAS after microwave extraction and off-line separation of iAs by solid phase extraction (SPE), EN 16278:2012 ${ }^{10}$. This method which proved to be fit for analyzing iAs in feed could lack the sensitivity required to determine iAs in food of non-marine origin, which according to EFSA seems to be the main dietary contributors in Europe ${ }^{3}$. However, the same group that developed and validated EN 16278:2012 tested and successfully applied and validated the method to determine iAs in seafood and rice in a collaborative trial ${ }^{11,12}$.

An alternative method for the determination of iAs in food matrices after selective extraction of iAs into chloroform and further quantification by HG-AAS, was recently validated by the Joint Research Centre (JRC) in a collaborative trial ${ }^{13}$. The selectivity of the method is better than that of direct HG-AAS and is easy to implement not requiring the use of sophisticated instrumentation such as HPLC-ICP-MS. In this manuscript, the feasibility of using this method to determine iAs in a wide range of food matrices: vegetables, grains, mushrooms and food of marine origin, has been evaluated. Furthermore, the performance of laboratories that used the method in proficiency tests organized by the EURL-HM and the JRC covering several matrices is described.

\section{Protocol}

NOTE: All the material used needs to be decontaminated with $10 \%(\mathrm{~m} / \mathrm{v}) \mathrm{HNO}_{3}$ and rinsed at least twice with deionized water.

\section{Hydrolysis}

1. Weigh accurately ca. 0.5 to $1 \mathrm{~g}$ of lyophilized sample (or the equivalent quantity of freshly homogenized sample e.g. 1 to $4 \mathrm{~g}$ ) in a $50 \mathrm{~mL}$ polypropylene centrifuge tube with screw cap.

2. Add $4.1 \mathrm{~mL}$ of deionized water.

3. Agitate with a mechanical shaker for about $5 \mathrm{~min}$ until the sample is completely wet.

4. Add $18.4 \mathrm{~mL}$ of concentrated hydrochloric acid $(\mathrm{HCl})$, not less than $37 \% \mathrm{~m} / \mathrm{v}$.

5. Agitate with a mechanical shaker for $15 \mathrm{~min}$.

6. Let rest for $12-15 \mathrm{~h}$ (for instance overnight).

\section{Extraction}

1. Add $2 \mathrm{~mL}$ of hydrogen bromide $(\mathrm{HBr})$ not less than $48 \% \mathrm{~m} / \mathrm{v}$ and $1 \mathrm{~mL}$ of hydrazine sulfate $\left(\mathrm{N}_{2} \mathrm{H}_{6} \mathrm{SO}_{4}\right)$ solution $(15 \mathrm{mg} / \mathrm{mL})$ to the hydrolyzed sample.

2. Shake for $30 \mathrm{~s}$ with a mechanical shaker.

3. Add $10 \mathrm{~mL}$ of chloroform $\left(\mathrm{CHCl}_{3}\right)$.

4. Shake for 5 min with a mechanical shaker.

5. Centrifuge for $5 \mathrm{~min}$ at $800 \mathrm{xg}$.

6. Pipette the chloroform phase (lower phase) into another $50 \mathrm{~mL}$ polypropylene centrifuge tube.

7. Add again $10 \mathrm{~mL}$ chloroform to the remaining acid phase and repeat the extraction. At the end around $20 \mathrm{~mL}$ of chloroform should have been collected. Take care to avoid cross-contamination from the acid phase.

\section{Clean-up of the Chloroform Phase}

1. Centrifuge the pooled chloroform phases for $5 \mathrm{~min}$ at $800 \mathrm{xg}$. The centrifugation time or speed may be increased if needed to achieve a clear separation of the two phases.

2. Remove all acid phase residues remaining on the chloroform with a $1 \mathrm{~mL}$ pipette. This step is crucial. Any acid phase residues remaining in the chloroform phase will lead to overestimated iAs results because all other arsenic species in the sample are present in the acid phase.

3. Filter through a hydrophobic PTFE membrane (25 $\mathrm{mm}$ diameter) to remove the remaining solid or acid phase residues present in the chloroform phase and collect the chloroform phase in a $50 \mathrm{~mL}$ polypropylene centrifuge tube.

\section{Back-extraction}

1. Add $10 \mathrm{~mL}$ of $1 \mathrm{M} \mathrm{HCl}$ to back extract iAs from the chloroform phase collected after the filtration step.

2. Shake for 5 min with a mechanical shaker.

3. Centrifuge for $5 \mathrm{~min}$ at $800 \mathrm{xg}$.

4. Pipette the acid phase (upper phase) and pour it into a $250 \mathrm{~mL}$ glass beaker (e.g. Pyrex) for mineralization.

5. Repeat the back-extraction and combine the collected $\mathrm{HCl}$ phases.

\section{Sample Mineralization}

Note: This step allows elimination of interferences and pre-concentration in samples in which the iAs mass fraction is close to or below the quantification limit, and it is frequently omitted by laboratories which use this protocol with ICP-MS for final determination instead of HG-AAS . 
1. Suspend $20 \mathrm{~g}$ of magnesium nitrate hexahydrate $\left[\mathrm{Mg}\left(\mathrm{NO}_{3}\right)_{2} 6 \mathrm{H}_{2} \mathrm{O}\right]$ and $2 \mathrm{~g}$ of magnesium oxide (MgO) in $100 \mathrm{~mL}$ of deionized water. Add 2.5 $\mathrm{mL}$ of this suspension to the glass beaker. Shake the suspension while adding it to avoid precipitation.

2. Add $10 \mathrm{~mL}$ of concentrated $\mathrm{HNO}_{3}$ of at least $65 \% \mathrm{~m} / \mathrm{v}$ and evaporate to dryness in a sand bath (or a thermal plate), avoiding any projections. To verify that the samples are totally dry, place a watch glass on top of the glass beaker and check that no condensation is formed.

3. Cover the beakers with watch glasses and place them in a muffle furnace at an initial temperature not exceeding $150{ }^{\circ} \mathrm{C}$ and progressively increase the temperature to $425 \pm 25^{\circ} \mathrm{C}$ at a rate of $50^{\circ} \mathrm{C} / \mathrm{h}$. Maintain at $425^{\circ} \mathrm{C}$ for $12 \mathrm{~h}$. This step is critical. To avoid any projections the rate of increase in temperature must be strictly implemented.

4. Allow the ashes to cool down to room temperature.

5. Add $0.5 \mathrm{~mL}$ of deionized water to wet the ash and add then $5 \mathrm{~mL}$ of $6 \mathrm{M} \mathrm{HCL}$. Take care to recover all the ash from the walls of the glass beaker. Dissolve the ash completely, shaking if necessary.

6. Add $5 \mathrm{~mL}$ of pre-reducing agent, prepared by dissolving $5 \mathrm{~g}$ of potassium iodide (KI), and $5 \mathrm{~g}$ of ascorbic acid in $100 \mathrm{~mL}$ of deionized water, and wait 30 min to achieve a quantitative reduction of iAs to As(III).

7. Filter the solution through a Whatman number 1 paper or equivalent and collect it in a $50 \mathrm{~mL}$ polypropylene centrifuge tube. Rinse the glass beaker twice with $6 \mathrm{M} \mathrm{HCl}$. Collect the rinsing liquids in a $25 \mathrm{~mL}$ tube and make it up to a final volume with $6 \mathrm{M} \mathrm{HCl}$ NOTE: When the iAs concentration in a sample is expected to be close or below the quantification limit of the method $(0.010 \mathrm{mg} / \mathrm{kg})$, or on the contrary, high, the mineralization steps 5.5-5.7 should be modified using the volumes given in Table 1, which would provide a lower quantification limit. Re-dissolved and pre-reduced samples are stable for $24 \mathrm{~h}$ at $4{ }^{\circ} \mathrm{C}$. At least two reagent blanks should be used for the whole analytical process.

\section{Calibration}

NOTE: For quantification purposes use an external calibration curve of As(III) in the range $0.5-10 \mu \mathrm{g} / \mathrm{L}$. Use a $1000 \mathrm{mg} / \mathrm{L} \mathrm{As}(\mathrm{V}) \mathrm{commercially}$ available certified standard solution to construct the calibration curve applying subsequent dilutions.

1. Prepare a $10 \mathrm{mg} / \mathrm{L} \mathrm{As}(\mathrm{V})$ standard solution by pipetting $1 \mathrm{~mL}$ of the $1,000 \mathrm{mg} / \mathrm{L}$ standard solution in a $100 \mathrm{~mL}$ volumetric flask and filling to the mark with $6 \mathrm{M} \mathrm{HCl}$.

2. Prepare a $0.1 \mathrm{mg} / \mathrm{L} \mathrm{As}(\mathrm{V})$ standard solution by pipetting $1 \mathrm{~mL}$ of the $10 \mathrm{mg} / \mathrm{L} \mathrm{As}(\mathrm{V})$ standard solution in a $100 \mathrm{~mL}$ volumetric flask and filling to the mark with $6 \mathrm{M} \mathrm{HCl}$.

3. Prepare a $25 \mu \mathrm{g} / \mathrm{L} \mathrm{As}(\mathrm{V})$ standard solution pipetting $25 \mathrm{~mL}$ of the $0.1 \mathrm{mg} / \mathrm{L} \mathrm{As}(\mathrm{V})$ standard solution in a $100 \mathrm{~mL}$ volumetric flask and filling to the mark with $6 \mathrm{M} \mathrm{HCl}$.

4. Prepare the calibration curve of $\mathrm{As}(\mathrm{III})$ as follows: pipette from the $25 \mu \mathrm{g} / \mathrm{L} \mathrm{As}(\mathrm{V})$ standard solution the volumes given in Table 2 into 50 $\mathrm{mL}$ volumetric flask, add $10 \mathrm{~mL}$ of the pre-reducing solution in each volumetric flask, wait $30 \mathrm{~min}$, then fill to the mark with $6 \mathrm{M} \mathrm{HCl}$. Other volumes are suitable provided that they maintain the proportions described above.

5. Prepare a calibration blank as follows: pipette $10 \mathrm{~mL} 6 \mathrm{M} \mathrm{HCl}$ and $10 \mathrm{~mL}$ pre-reducing solution in a $50 \mathrm{~mL}$ volumetric flask. Wait $30 \mathrm{~min}$ and fill then to the mark with $6 \mathrm{M}$

6. Use the standards marked as QC1 and QC2 in Table 2 as quality control: QC1 ensures that the quantification at low concentration level is correct and QC2, ensures that the response is stable at high concentrations, with no significant drift in time.

\section{Determination}

1. Use an atomic absorption spectrometer equipped with an auto-sampler, a flow injection-hydride generation system, and an electro-thermally heated quartz cell for detection and quantification purposes, following the instrumental conditions for quantification of iAs by FI-HG-AAS as listed in Table 3.

\section{Quantification}

1. Calculate the iAs mass fraction in the samples analyzed (expressed in $\mathrm{mg} / \mathrm{kg}$ ), using the following equation:

$$
i A s=\frac{V \cdot\left(C_{x}-C_{B I}\right)}{1000 \cdot w}
$$

Where:

$\mathrm{C}_{\mathrm{x}}$ : Concentration in the extract $(\mu \mathrm{g} / \mathrm{L})$, calculated from the calibration curve

$\mathrm{C}_{\mathrm{BI}}$ : Concentration in the reagent blank sample $(\mu \mathrm{g} / \mathrm{L})$, extrapolated from the calibration curve

$\mathrm{V}$ : Final volume of the sample mineralization step (5.7), usually $\mathrm{V}=25 \mathrm{~mL}$

w: Weight of sample (in grams)

\section{Representative Results}

The method was applied to determine the iAs mass fraction in several food commodities purchased from various Spanish markets. The results obtained with this method for a series of different matrices are classified in Table $\mathbf{4}$ following the categories used by EFSA ${ }^{3}$ in a report in which dietary exposure to inorganic arsenic in the European population is evaluated on the basis of data reported by Official Control Laboratories $(\mathrm{OCL})$. The results in Table 4 represent the mean of three replicates \pm the reproducibility standard deviation $\left(\mathrm{S}_{\mathrm{R}}\right)$ for the different food categories, calculated during the collaborative trial in which the present method was validated ${ }^{13}$. The results shown in Table 4 are in good agreement with other previously published in similar matrices ${ }^{11,12,14}$. 
Of particular relevance are the results obtained for iAs in different types of rice because maximum limits are included for them in the European legislation for contaminants in food ${ }^{1}$. The highest values being obtained for brown rice and the lowest for white rice, in agreement with the findings of the $\mathrm{OCLs}^{3}$. The highest levels were found for the sea weed Hizikia fusiforme, whose consumption has been discouraged by several authorities as indicated in the report by EFSA.

The performance of laboratories that participated in PTs organized by the EURL-HM and the JRC and that used this method for the determination of iAs, has been compared to the performance of laboratories using other methods. Most of the other methods are based on HPLC-ICP-MS (around 50\% of the evaluated results) and on HG-AAS without previous separation of iAs from other arsenic species (25\% of the total), Figure 1. Other approaches used (around $15 \%$ of the evaluated results), were based on electrothermal atomization (ETAAS), fluorescence detection and ICP coupled to atomic emission spectroscopy (ICP-AES), with and without hydride generation, and are evaluated together under the name "Other methods" because the individual numbers would be too few to be of any statistical significance.

Some of the laboratories that have used the evaluated method introduced some variations to the original protocol and used ICP-MS instead of FI-HG-AAS. Frequently those laboratories did not apply the dry ashing step (Step 5 in the protocol) and just introduced the $1 \mathrm{M} \mathrm{HCl} \mathrm{phase} \mathrm{into}$ the ICP-MS. The PTs evaluated covered various matrices: rice ${ }^{15,16}$, wheat, spinach, algae ${ }^{17}$ and chocolate ${ }^{18}$.

The performance of laboratories was expressed as z-score:

$z=\frac{x_{l a b}-X_{r e f}}{\sigma}$

Where:

$\mathrm{X}_{\mathrm{lab}}$ is the measurement result reported by a participant in a PT

$\mathrm{X}_{\text {ref }}$ is the assigned value (used to benchmark laboratories). In all PTs dealt within this paper the assigned value was established by a group of expert laboratories in the field of iAs analysis using different analytical methods.

$\sigma \quad$ is the standard deviation for proficiency assessment, fixed by the PT provider taking into consideration the state of the art in a certain area of analysis. In the PTs considered in this paper $\sigma$ was $15 \%$ of the assigned value for rice and wheat, $22 \%$ in algae and $25 \%$ for spinach and chocolate.

The interpretation of the $z$ score is done according to ISO $17043: 2010^{19}$ :

$\mid$ score $\leq 2 \quad$ satisfactory (S) performance

$2<\mid$ score $\mid<3$ questionable $(Q)$ performance

$\mid$ score $\mid \geq 3 \quad$ unsatisfactory $(U)$ performance

Seventy-five per cent of the results obtained with the method described above, got a satisfactory z-score. The determination of the iAs mass fraction in algae turned out to be challenging as expected, taking into consideration the complex distribution of arsenic species in matrices of marine origin. Two out of the three values reported in IMEP-112 for iAs in algae, using this method, got an unsatisfactory z-score. The same difficulty was observed among the results obtained with other methods. Excluding the results reported for iAs in algae, $85 \%$ of the results obtained with the evaluated method were satisfactory. 


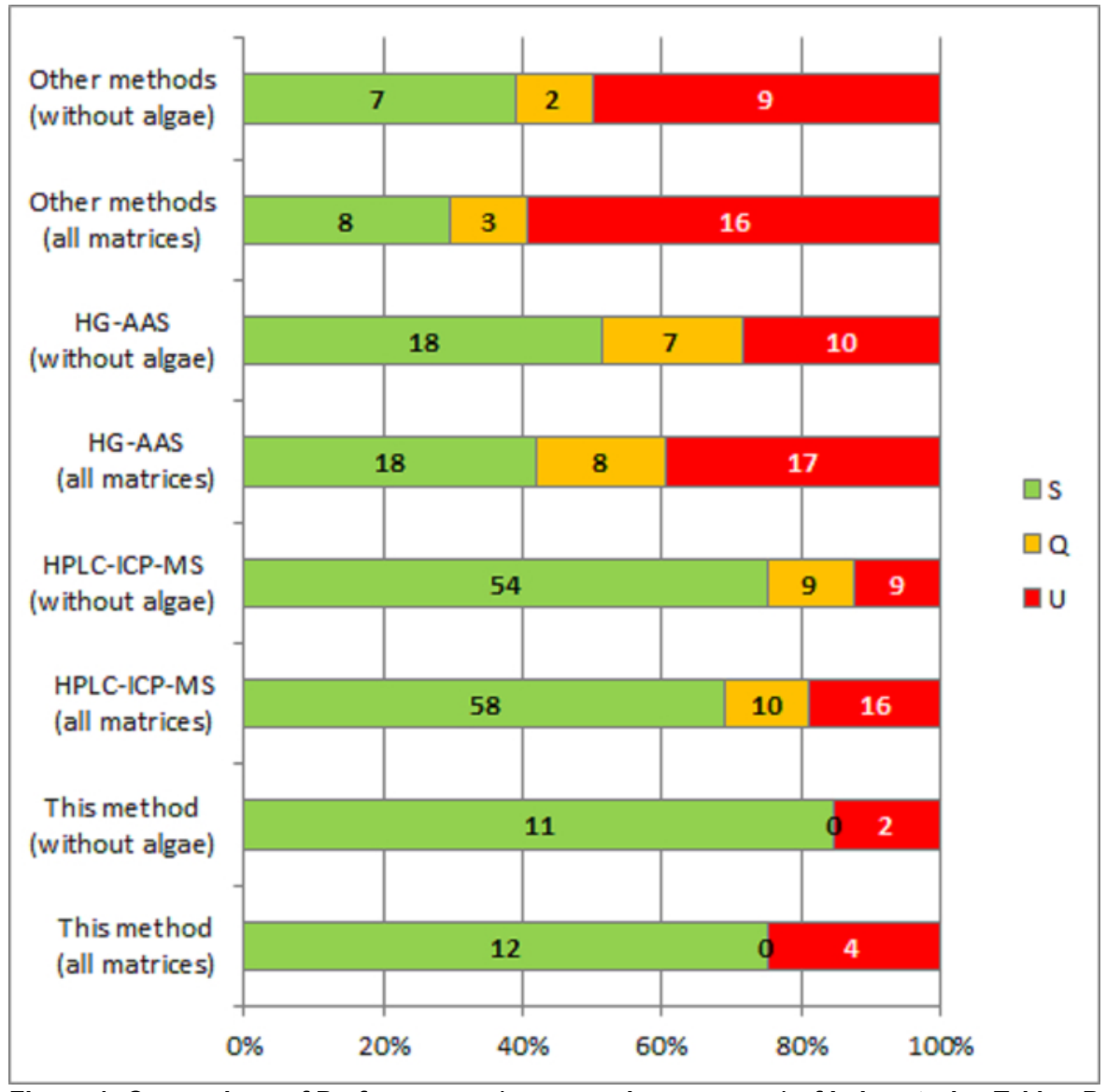

Figure 1: Comparison of Performances (expressed as z-scores) of Laboratories Taking Part in PTs (IMEP-107, IMEP-112, EURL-HM-20 and IRMM-PT-43) with the Method Described in this Paper and with Other Commonly Applied Methods. S: satisfactory, Q: questionable and U: unsatisfactory. Please click here to view a larger version of this figure.

\begin{tabular}{|l|l|l|}
\hline & $\begin{array}{l}\text { Expected iAs mass fraction } \\
\text { lower than } \mathbf{0 . 0 1 0} \mathbf{~ m g} / \mathbf{k g}\end{array}$ & $\begin{array}{l}\text { Expected iAs mass fraction } \\
\text { higher than what is covered } \\
\text { by the calibration curve }\end{array}$ \\
\hline $\begin{array}{l}6 \mathrm{~mol} \mathrm{~L}-1 \mathrm{HCL} \text { volume used to re-dissolve } \\
\text { the ashes }(\mathrm{mL})\end{array}$ & 2 & 10 \\
\hline Pre-reducing agent volume $(\mathrm{mL})$ & 2 & 10 \\
\hline Final volume $(\mathrm{mL})$ & 10 & 50 \\
\hline
\end{tabular}

Table 1: Modifications of the Protocol when Analyzing Samples in which Very Low or Very High iAs Concentrations are Expected.

\begin{tabular}{|l|l|}
\hline $\begin{array}{l}\text { Concentration in the } \\
\text { calibration curve }(\boldsymbol{\mu g} / \mathrm{L})\end{array}$ & Aliquot $(\mathrm{mL})$ \\
\hline 0.5 & 1 \\
\hline 1 & $2(\mathrm{QC} 1)$ \\
\hline 2.5 & 5 \\
\hline 5 & $10(\mathrm{QC} 2)$ \\
\hline 7.5 & 15 \\
\hline 10 & 20 \\
\hline All As(III) calibration standard solutions shall be prepared freshly before each calibration. \\
\hline
\end{tabular}

Table 2: Aliquots to be taken from the $25 \mu \mathrm{g} / \mathrm{L} \mathrm{As}(\mathrm{V})$ standard solution to construct the $\mathrm{As}$ (III) calibration curve in a $50 \mathrm{~mL}$ final volume. 


\begin{tabular}{|c|c|}
\hline \multirow[t]{4}{*}{$\begin{array}{l}\text { Flow injection } \\
\text { Hydride generation }\end{array}$} & $\begin{array}{l}\text { Loop sample: } 0.5 \mathrm{~mL} \text { (To be adapted when the reconstitution } \\
\text { volume of the final pre-reducing solution is different from } 25 \mathrm{~mL} \text { ). }\end{array}$ \\
\hline & $\begin{array}{l}\text { Reducing agent: } 0.2 \%(w / v) \mathrm{NaBH}_{4} \text { in } 0.05 \%(\mathrm{w} / \mathrm{v}) \mathrm{NaOH} ; 5 \mathrm{~mL} / \\
\text { min flow rate. }\end{array}$ \\
\hline & $\mathrm{HCl}$ solution $10 \%(\mathrm{v} / \mathrm{v}), 10 \mathrm{~mL} / \mathrm{min}$ flow rate. \\
\hline & - $\quad$ Carrier gas: Argon, $100 \mathrm{~mL} / \mathrm{min}$ flow rate. \\
\hline \multirow{3}{*}{$\begin{array}{l}\text { Atomic absorption } \\
\text { spectrometer }\end{array}$} & Electrodeless discharge lamp system 2 \\
\hline & Lamp current setting: $400 \mathrm{~mA}$ \\
\hline & Cell temperature: $900^{\circ} \mathrm{C}$ \\
\hline
\end{tabular}

Table 3: Instrumental Conditions used for iAs Quantification by HG-AAS. 


\begin{tabular}{|c|c|c|}
\hline \multicolumn{2}{|l|}{ Food } & \multirow[t]{2}{*}{ i-As ( $\mu \mathrm{g} / \mathrm{kg}$ fresh weight) } \\
\hline Grain and grain-based & & \\
\hline \multirow[t]{10}{*}{ Rice } & White & $113 \pm 18$ \\
\hline & & $73 \pm 12$ \\
\hline & & $56 \pm 9$ \\
\hline & Brown & $197 \pm 32$ \\
\hline & & $125 \pm 20$ \\
\hline & & $275 \pm 44$ \\
\hline & Parboiled & $134 \pm 21$ \\
\hline & & $159 \pm 25$ \\
\hline & Wafers & $162 \pm 26$ \\
\hline & & $127 \pm 20$ \\
\hline \multicolumn{3}{|c|}{ Vegetable and vegetable products } \\
\hline \multirow[t]{5}{*}{ Dehydrated mushroom } & Boletus edulis & $174 \pm 10$ \\
\hline & Galocybe gambosa & $74 \pm 4$ \\
\hline & Marasmius oreades & $104 \pm 6$ \\
\hline & Cantharellus lutescens & $16 \pm 1$ \\
\hline & Lentinula edodes & $96 \pm 6$ \\
\hline \multirow[t]{4}{*}{ Sea weed } & Hizikia fusiforme & $97000 \pm 14550$ \\
\hline & & $44943 \pm 6742$ \\
\hline & Fucus vesiculosus & $288 \pm 43$ \\
\hline & & $433 \pm 65$ \\
\hline \multicolumn{3}{|l|}{ Fish and other seafood } \\
\hline \multirow[t]{8}{*}{ Fish meat } & Flathead grey mullet & $53 \pm 12$ \\
\hline & & $21 \pm 5$ \\
\hline & European eel & $72 \pm 16$ \\
\hline & & $42 \pm 9$ \\
\hline & Crayfish & $33 \pm 7$ \\
\hline & & $20 \pm 4$ \\
\hline & Tuna & $11 \pm 2$ \\
\hline & & $5 \pm 1$ \\
\hline \multirow[t]{4}{*}{ Molluscs } & Clam & $243 \pm 54$ \\
\hline & & $133 \pm 29$ \\
\hline & Mussel & $32 \pm 32$ \\
\hline & & $139 \pm 31$ \\
\hline
\end{tabular}

Table 4: Results Obtained for a Range of Different Matrices Applying the Described Method.

\section{Discussion}

A critical step in the described protocol is the clean-up of the chloroform phase (Step 3.2) because any acid phase residues remaining in the chloroform phase will lead to overestimated iAs results since all other arsenic species in the sample are present in the acid phase. This is of particular relevance when analyzing marine samples due to the presence of a plethora of organic species, which could account for most of the arsenic mass fraction present in the sample. The use of a hydrophobic PTFE (3.3) membrane is of paramount importance. If an emulsion is formed during the extraction of iAs into chloroform, the speed of centrifugation (3.1) can be increased. Other traditional approaches to eliminate emulsions can also be applied. Another critical step is the mineralization (Step 5.3). The rate of increase in temperature must be strictly implemented to avoid any projections which would reduce the iAs recovery leading to an uncontrolled negative bias and could be dangerous for the analyst. 
As mentioned above some laboratories have used the evaluated method using ICP-MS instead of FI-HG-AAS. In such a case the dry ashing step (Step 5 in the protocol) is not needed and the $1 \mathrm{M} \mathrm{HCl}$ phase can be introduced into the ICP-MS. In the case of HG-AAS, due to its higher detection limit, a pre-concentration step which also eliminates possible interferences, is needed.

The percentage of satisfactory results obtained with the method described in this paper, both with and without the results reported for algae, is comparable to that of HPLC-ICP-MS and higher than that of HG-AAS. The latter technique (HG-AAS) is widely available but prone to interferences from organic arsenic species, especially in food commodities with a complex arsenic species distribution pattern. The lowest percentage of satisfactory results characterizes those obtained with "Other methods" but it must be kept in mind that it covers several analytical approaches, each one of them represented by a small amount of results, Figure 1. The method presented in this paper is an alternative to the more sophisticated/expensive HPLC-ICP-MS, still being characterized by a similar performance even in complex matrices. Frequently the use of hyphenated techniques, such as HPLC-ICP-MS, requires highly qualified operators and expensive infra-structures. The method presented in this paper can be implemented by any analyst trained in basic analytical chemistry.

There are some main drawbacks associated to the method. It is time-consuming since several steps must be followed to separate iAs from other arsenic species and to pre-concentrate iAs down to even sub-ppm levels. It implies the use of chloroform. There is a tendency to avoid the use of chlorinated compounds in the laboratories, due to the negative health effects that they could have. Nevertheless, if good laboratory practices are kept and samples are handled in fume hoods, those negative effects could be avoided. MMA will interfere in the determination of iAs. This must be kept in mind when analyzing samples in which MMA could be present, such as algae, fish and other seafood. However, MMA is normally present in small amounts which would be covered by the uncertainty associated to the results obtained for iAs.

\section{Disclosures}

The authors have nothing to disclose.

\section{Acknowledgements}

The authors thank Dr. F. Cordeiro of the JRC for the useful discussions about statistical treatment of data. Expert laboratories in the analysis of iAs in biological matrices that provided results to be used as assigned value in PTs and laboratories that took part in the studied PTs are acknowledged.

\section{References}

1. Commission Regulation (EC) 1881/2006 setting maximum levels for certain contaminants in foodstuffs. issued by the European Commission. OJ, L364/5 (2006).

2. EFSA Panel on Contaminants in the Food Chain (CONTAM); Scientific Opinion on Arsenic in Food. EFSA J. 7 (10), 1351 (2009).

3. European Food Safety Authority, Dietary exposure to inorganic arsenic in the European population. EFSA J. 12 (3), 3597 (2014).

4. de la Calle, M.B., et al. Does the determination of inorganic arsenic in rice depend on the method?, TrAC. 30 (4), $641-651$ (2011).

5. GB/T5009.11-2003. Determination of total arsenic and abio-arsenic in foods. (2003).

6. EN 15517:2008 Determination of trace elements-Determination of inorganic As in seaweed by hydride generation atomic absorption spectrometry (HG-AAS) after digestion. European Committee for Standardisation (2008).

7. de la Calle, M.B., et al. Is it possible to agree on a value for inorganic arsenic in food? The outcome of IMEP-112, Anal Bioanal Chem. 404, 2475-2488 (2012).

8. Schmeisser, E., Goessler, W., Kienzl, N., Francesconi, K. Volatile analytes formed from arsenosugars: determination by HPLC-HG-ICPMS and implications for arsenic speciation analyses. Anal. Chem. 76, 418-423 (2004).

9. EN 16802:2016. Foodstuffs. Determination elements and their chemical species. Determination of inorganic arsenic in foodstuffs of marine and plant origin by anion-exchange HPLC-ICP-MS (2016).

10. BS EN 16278:2012. Animal feeding stuffs - Determination of inorganic arsenic by hydride generation atomic absorption spectrometry (HGAAS) after microwave extraction and separation by solid phase extraction (SPE). European Committee for Standardisation (2012).

11. Rasmussen, R.R., Qian, Y., Sloth, J.J., SPE HG-AAS method for the determination of inorganic arsenic in rice. Results from method validation studies an a survey on rice products. Anal Bioanal Chem. 405, 7851-7857 (2013).

12. Rasmussen, R.R., Hedegaard, R.V., Larsen, E.H., Sloth, J.J. Development and validation of a method for the determination of inorganic arsenic in rice. Results from method validation studies and a survey on rice products. Anal Bioanal Chem. 403, 2825-2834 (2012).

13. Fiamegkos, I., Accuracy of a method based on atomic absorption spectrometry to determine inorganic arsenic in food: Outcome of the collaborative trial IMEP-41, Food Chem. 213, 169-179, (2016).

14. Llorente-Mirandes, T., Barbero, M., Rubio, R., López-Sánchez, J.F. Occurrence of inorganic arsenic in edible Shiitake (Lentinula edodes) Products, Food Chem. 158, 207-215, (2014).

15. de la Calle, M.B., Linsinger, T., Emteborg, H., Charoud-Got, J., Verbist, I. Report of the seventh interlaboratory comparison organised by the European Union-Reference Laboratory for Heavy Metals in Feed and Food. IMEP-107: Total and inorganic As in rice. EUR 24314 EN (2010).

16. Cordeiro F., Cizek-Stroh, A., de la Calle, B. Determination of total and inorganic arsenic in rice. IRMM-PT-43 Proficiency Test Report. EUR 28100 EN (2016).

17. de la Calle, M.B., et al. IMEP-112: Total and inorganic arsenic in wheat, vegetable food and algae. EUR 24937 EN (2011).

18. Fiamegkos, I., et al. Determination of total $\mathrm{As}, \mathrm{Cd}, \mathrm{Pb}, \mathrm{Hg}$ and inorganic arsenic in chocolate. EURL-HM-20 Proficiency test Report. JRC $98502(2015)$

19. ISO 17043 "Conformity assessment - General requirements for proficiency testing", issued by ISO-Geneva (CH), International Organization for Standardization. (2010). 